\title{
Mineralocorticoid Receptor Stimulation Improves Cognitive Function and Decreases Cortisol Secretion in Depressed Patients and Healthy Individuals
}

\author{
Christian Otte*,', Katja Wingenfeld', Linn K Kuehl', Michael Kaczmarczyk', Steffen Richter', \\ Arnim Quante', Francesca Regen', Malek Bajbouj', Frank Zimmermann-Viehoff', Klaus Wiedemann ${ }^{2}$ and \\ Kim Hinkelmann'
}

'Department of Psychiatry and Psychotherapy, Charité University Medical Center, Campus Benjamin Franklin, Berlin, Germany; ${ }^{2}$ Department of Psychiatry and Psychotherapy, University Medical Center Hamburg-Eppendorf, Hamburg, Germany

Memory and executive function are often impaired in patients with major depression, while cortisol secretion is increased. Mineralocorticoid receptors (MR) are abundantly expressed in the hippocampus and in the prefrontal cortex, brain areas critical for memory, executive function, and cortisol inhibition. Here, we investigated whether MR stimulation with fludrocortisone (I) improves memory and executive function and (2) decreases cortisol secretion in depressed patients and healthy individuals. Twenty-four depressed patients without medication and 24 age-, sex-, and education-matched healthy participants received fludrocortisone (0.4 mg) or placebo in a randomized, double-blind, within-subject cross-over design. We measured verbal memory, visuospatial memory, executive function, psychomotor speed, and salivary cortisol secretion during cognitive testing between I 400 and I700 hours. For verbal memory and executive function, we found better performance after fludrocortisone compared with placebo across groups. No treatment effect on other cognitive domains emerged. Depressed patients performed worse than healthy individuals in psychomotor speed and executive function. No group effect or group $\times$ treatment interaction emerged on other cognitive domains. Fludrocortisone decreased cortisol secretion across groups and there was a significant correlation between cortisol inhibition and verbal memory performance. Our data suggest a crucial role of MR in verbal memory and executive function and demonstrate the possibility to improve cognition in depressed patients and healthy individuals through MR stimulation.

Neuropsychopharmacology (20I5) 40, 386-393; doi:I0.1038/npp.20I4.I8I; published online I3 August 20I4

\section{INTRODUCTION}

Patients with major depression often exhibit cognitive deficits. Memory and executive function are among those domains that are most consistently impaired in depressed patients. Importantly, several groups have found impaired memory and executive function to be associated with elevated cortisol in patients with major depression (Behnken et al, 2013; Gomez et al, 2006; Hinkelmann et al, 2009, 2013; O'Hara et al, 2007) although not all studies concur (Krogh et al, 2012).

Cortisol exerts its effects in the brain via two different nuclear receptors, the mineralocorticoid receptor (MR) and the glucocorticoid receptor (GR). GR are distributed throughout the brain and have a low affinity for cortisol, whereas MR have a high cortisol affinity and are expressed primarily in limbic areas. Both receptors are abundantly

\footnotetext{
*Correspondence: Professor C Otte, Department of Psychiatry and Psychotherapy, Charité University Medical Center, Campus Benjamin Franklin, I4050 Berlin, Germany, Tel: +49 3084458253 , Fax: +49 308445 8255, E-mail: christian.otte@charite.de Received 30 April 2014; revised 16 June 2014; accepted 25 June 20।4; accepted article preview online 18 July 2014
}

expressed in the hippocampus and in the prefrontal cortex, brain areas critical for memory and executive function (Rock et al, 2013; Trivedi and Greer, 2014; Wagner et al, 2012). Lately, animal and human studies have revealed the existence of a membrane-bound MR-mediating rapid non-genomic effects with an intermediate cortisol affinity (Henckens et al, 2011; Joels et al, 2013; van Ast et al, 2013). Both GR and MR inhibit cortisol secretion through negative feedback inhibition (de Kloet, 2013). Although GR alterations leading to high cortisol and impaired cognitive function have been consistently described in major depression (Herbert, 2013; Pariante and Lightman, 2008), much less is known about the role of MR in cortisol secretion and cognitive function.

Animal studies have consistently shown a role for the MR in cortisol secretion and memory performance and executive function (Joels et al, 2008). For example, blockade of MR impairs spatial memory (Berger et al, 2006; Brinks et al, 2009; Qiu et al, 2010; ter Horst et al, 2012), and working memory (Berger et al, 2006). In contrast, the overexpression of MR has been consistently associated with improved memory in animals (Ferguson and Sapolsky, 2008; Harris et al, 2013; Lai et al, 2007; Rozeboom et al, 2007). In healthy 
humans, blockade of the MR impaired memory and executive function in young healthy men and increased cortisol secretion (Cornelisse et al, 2011; Otte et al, 2007; Rimmele et al, 2013). Furthermore, MR stimulation with the agonist fludrocortisone inhibits cortisol secretion in humans (Buckley et al, 2007; Otte et al, 2003, 2010a). However, this inhibition is attenuated in patients with psychotic depression suggesting impaired MR function in these patients (Lembke et al, 2013). Importantly, psychotically depressed patients show the most severe cognitive deficits (Schatzberg et al, 2000). Furthermore, there is evidence of decreased MR expression in the hippocampus and prefrontal cortex in depressed patients (Klok et al, 2011a; Medina et al, 2013). Finally, GR blockade with mifepristone improved cognitive function in bipolar depressed patients and the authors speculated that this might be due to an increased MRmediated signal (Watson et al, 2012).

In sum, there is a plethora of data suggesting an important role of MR function on cognition in healthy individuals (Joëls et al, 2008) and first evidence of impaired MR function in major depression (Klok et al, 2011a; Medina et al, 2013). However, so far no study directly examined a potential therapeutic effect of MR stimulation, neither in healthy individuals nor in depressed patients. Therefore, we examined the acute effects of the MR agonist fludrocortisone on memory and executive function as well as cortisol secretion in depressed patients and age-, sex-, and education-matched healthy controls. We hypothesized that, in both groups, fludrocortisone would improve memory and executive function and decrease cortisol secretion.

\section{PATIENTS AND METHODS}

\section{Participants}

We recruited 24 unmedicated depressed patients according to DSM-IV criteria from a specialized depression clinic at the Department of Psychiatry and Psychotherapy, Charité University Medical School, Berlin. Inclusion criteria were (1) a diagnosis of major depressive disorder, single, or recurrent according to DSM-IV criteria; (2) a minimum baseline score of 18 points on the Hamilton Rating Scale for Depression, 17-item version (HDRS-17); (3) age from 18 to 40 years; and (4) a period of at least 3 days free from antidepressants, antipsychotics, mood stabilizers, and other medications influencing HPA activity. Only sleep medication and benzodiazepines as needed were allowed and only three patients used sleep medication or benzodiazepines during the days of testing. About half of the patients refered were first-episode patients and therefore drug naïve. The remaining patients were referred either untreated or with major depression despite medication. The latter group went through a 3-day washout and was switched to a different medication immediately after the examination. No patient experienced discontinuation symptoms from cessation of medication.

Criteria for exclusion were (1) dementia, schizophrenia spectrum disorder, bipolar disorder, substance dependence within the last 6 months according to the Mini-International Neuropsychiatric Interview (MINI) (Sheehan et al, 1998); (2) serious medical conditions, especially those associated with adrenal dysfunctions, steroid use, or well-known impact on HPA activity (eg, diabetes mellitus) or cognitive function; (3) pregnancy and nursing; and (4) fluoxetine medication due to long half-life time.

A control group of 24 healthy subjects recruited by public postings and matched for age, sex, and years of education were enrolled in the study. Healthy subjects were free of former and present DSM-IV Axis I disorders according to the MINI, had no physical illness, and had been free of any medication at least 3 months. In patients and healthy individuals, depressive symptoms were assessed by the selfreport Beck Depression Inventory. The HDRS-17 as clinical interview was only applied in patients.

All participants underwent a screening procedure consisting of a medical and psychiatric history questionnaire (evaluating current lifetime psychiatric diagnosis and medical history, use of medication, alcohol, substance abuse, and smoking), and a routine medical examination. The study was approved by the local ethics committee. After complete description of the study to the subjects, written informed consent was obtained.

\section{Procedures}

Participants ingested four fludrocortisone ( $0.1 \mathrm{mg}$ each) pills (Astonin H, Merck Serono GmbH, Germany) or four identical looking placebo pills in a randomized order and a doubleblind, cross-over design with 3 days in between test days. The order of fludrocortisone and placebo administration was balanced. All subjects were tested in the afternoon between 1400 and 1700 hours with fludrocortisone being administered at 1400 hours. After a 90-minute break following drug administration, participants underwent cognitive testing. Blood pressure was assessed at 1400 hours (baseline), 1600, and 17:00 hours by an automatic device (Carescape V100, GE Healthcare). Salivary cortisol was collected during cognitive testing between 1400 and 1700 hours. Specifically, baseline samples were taken at 1350 and 1400 before medication intake. Afterward, samples were taken between 1500 and 1700 hours every half an hour. All samples were taken while study personnel were present. All participants received oral and written instructions on the correct use of the Salivette salivary collection device (Sarstedt AG, Nümbrecht, Germany).

\section{Neuropsychological Assessment}

Rey-Osterrieth complex figure test and Taylor complex figure test. These tests measure visuospatial memory (Osterrieth, 1944). The participant is first required to copy a complex figure. Immediately thereafter (direct recall) and 20 min later (delayed recall) the figure has to be re-drawn from memory.

Auditory verbal learning test. The auditory verbal learning test (AVLT) is a measure of short-term and longterm verbal memory (Lezak, 1995). The experimenter reads a list of 15 words (list A), which the participant is requested to repeat in loose order. After list A has been presented five times, the subject is asked to reproduce words from a newly presented list (list B). Following this, the subject is instructed to recall the words from list A without renewed presentation. After $30 \mathrm{~min}$, the subject is again asked to repeat the words from list A (delayed recall). 
Trail making test. Psychomotor speed was assessed with the trail making test (TMT) part A (Reitan, 1992). In this task, the subject has to connect encircled numbers in ascending order as quickly as possible. Part B assesses aspects of executive function, ie, cognitive set shifting and requires the alternation between numbers and letters, again in ascending order.

\section{Hormonal Assessment}

Cortisol was determined by radioimmunoassay (DRG, Marburg, Germany). Interassay and intra-assay coefficients of variation were below $8 \%$ and the detection limit was $0.5 \mathrm{ng} / \mathrm{ml}$.

\section{Statistical Analyses}

Demographic characteristics between depressed patients and healthy participants were compared using $t$-tests for continuous variables and $\chi^{2}$-tests for dichotomous variables. Separate (rm-ANOVA) with treatment (fludrocortisone $v s$ placebo) as within-subject factor and group (depressed patients $v s$ healthy controls) as between-subject factor were conducted to examine differences in blood pressure, memory, executive function, and cortisol secretion. We also calculated cortisol delta values (highest baseline value minus lowest value after placebo or fludrocortisone ingestion) for each condition. For all participants, the single lowest cortisol value was found during the last three measurement time points.

\section{RESULTS}

There were no significant differences between depressed patients and healthy controls on demographic variables. Information on demographic variables is given in Table 1.

\section{Psychomotor Speed: TMT A}

For psychomotor speed as dependent variable, rm-ANOVA with treatment (fludrocortisone $v s$ placebo) as within-subject factor and group (depressed $v s$ healthy controls) as

Table I Demographic and Clinical Variables

\begin{tabular}{lccc}
\hline & $\begin{array}{c}\text { Depressed patients } \\
\mathbf{N}=\mathbf{2 4}\end{array}$ & $\begin{array}{c}\text { Healthy controls } \\
\mathbf{N}=\mathbf{2 4}\end{array}$ & \\
\hline Mean age & $26.5 \pm 3.1$ & $26.8 \pm 3.5$ & NS \\
Sex, \% females & 70.8 & 70.8 & NS \\
Smoker, \% & 41.6 & 29.6 & NS \\
Education, years & 12.0 & 12.1 & NS \\
Body mass index & 23.3 & 23.2 & NS \\
BDI, mean & $31.8 \pm 7.6$ & $3.3 \pm 2.6$ & $p<0.001$ \\
HDRS- 17, mean & $24.8 \pm 4.8$ & - & - \\
\hline
\end{tabular}

Abbreviations: BDI, Beck Depression Inventory; HDRS- 17, Hamilton Depression Rating Scale - 17-item version; NS, not significant.

Comparisons between depressed patients and healthy controls based on one-way ANOVA for continuous variables and $\chi^{2}$-test for dichotomous variables. between-subject factor did not reveal a significant treatment effect $(\mathrm{F}=0.1, p=0.96)$ but a significant group effect $(\mathrm{F}=6.6, p=0.01)$ indicating slower psychomotor speed in depressed patients compared with healthy controls. There was no group $\times$ treatment interaction $(\mathrm{F}=0.05, p=0.83)$.

\section{Executive Function: TMT B}

To obtain a measure of executive function not influenced by psychomotor speed, we defined executive function as time TMT B minus time TMT A. Rm-ANOVA with treatment (fludrocortisone vs placebo) as within-subject factor and group (depressed patients $v s$ healthy controls) as betweensubject factor revealed a significant treatment effect $(\mathrm{F}=4.4$, $p=0.04$ ) indicating improved executive function after fludrocortisone across groups. As can be seen in Figure 1, the effects were much stronger in depressed patients that in healthy controls. Therefore, we conducted exploratory post hoc tests that confirmed significant treatment effects in the depressed patients $\left(\mathrm{F}=5.2, p=0.03\right.$, effect size partial $\eta^{2}$ : 0.18 ) but failed to find significant treatment effects in healthy individuals $(\mathrm{F}=0.35, p=0.56)$.

The group effect was not significant $(\mathrm{F}=1.4, p=0.24)$. There was no group $\times$ treatment interaction $(\mathrm{F}=1.0$, $p=0.32)$.

\section{Verbal Memory: AVLT}

Rm-ANOVA with treatment (fludrocortisone $v s$ placebo) as within-subject factor and group (depressed patients $v s$ healthy controls) as between-subject factor revealed a significant treatment effect for AVLT delayed recall $(\mathrm{F}=4.9$, $p=0.03$ ), indicating better verbal memory delayed recall in the fludrocortisone condition compared with placebo across groups. As can be seen in Figure 2, the effects were much stronger in depressed patients that in healthy controls. Therefore, we conducted exploratory post hoc tests that confirmed significant treatment effects in the depressed patients $\left(\mathrm{F}=4.2, p=0.05\right.$, effect size partial $\left.\eta^{2}: 0.15\right)$ but failed to find significant treatment effects in healthy individuals $(\mathrm{F}=0.36, p=0.55)$. There was neither a group

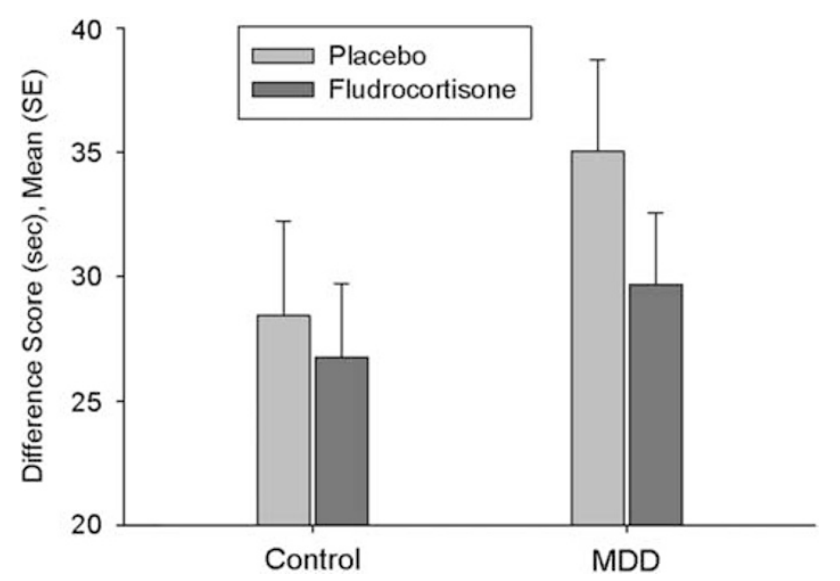

Figure I Executive function as measured by Trail Making Test $B$ minus Trail making test $A$ in seconds; treatment effect: $p=0.04$, group $\times$ treatment: $p=N S$, group effect $p=N S$. 


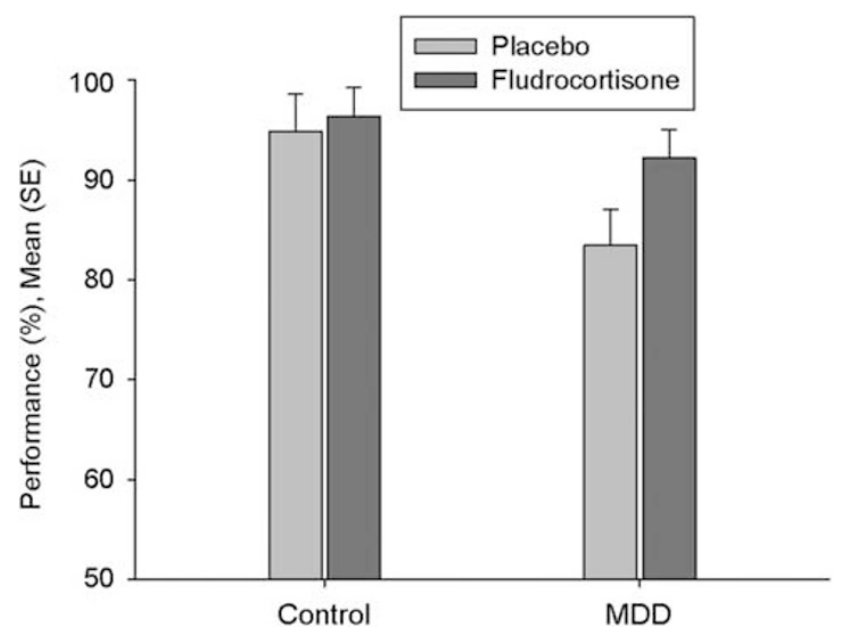

Figure 2 Verbal learning memory test; \% correct answers in delayed recall; treatment effect: $p=0.03$, group $\times$ treatment: $p=N S$, group effect $p=N S$.

effect $(\mathrm{F}=2.6, p=0.11)$ nor a treatment by group interaction $(\mathrm{F}=1.8, p=0.18)$.

With regard to the learning curve of the presented words during the five trials, there was no treatment effect $(\mathrm{F}=0.30, p=0.59)$ and no treatment $\times$ group interaction $(\mathrm{F}=0.21, p=0.65)$ but a significant group effect indicating impaired learning in depressed patients $v s$ healthy controls $(\mathrm{F}=5.1, p=0.03)$.

\section{Visuo Spatial Memory: Rey/Taylor Figure}

Rm-ANOVA with time (copy, direct recall, delayed recall) and treatment (fludrocortisone $v s$ placebo) as within-subject factor and group (depressed patients $v s$ healthy controls) as between-subject factor did not reveal a significant treatment effect $(\mathrm{F}=0.4, p=0.52)$, or group effect $(\mathrm{F}=2.6, p=0.11)$, or treatment $\times$ group interaction $(\mathrm{F}=1.4, p=0.24)$.

\section{Cortisol Secretion During Cognitive Testing}

Rm-ANOVA with time (seven time points) and treatment (fludrocortisone $v s$ placebo) as within-subject factor and group (depressed patients $v s$ healthy controls) as betweensubject factor revealed no significant treatment effect, group effect or group $\times$ treatment interaction. However, a significant treatment $\times$ time interaction $(\mathrm{F}=9.5, p<0.01)$ indicated stronger cortisol suppression after fludrocortisone compared with placebo (Figure 3). These results were corroborated by analyses using delta values, for which we found in ANOVA a significant treatment effect $(\mathrm{F}=8.2$, $p<0.01$ ), again suggesting greater cortisol suppression after fludrocortisone compared with placebo. No group effect $(\mathrm{F}=0.2, p=0.88)$ or group $\times$ treatment interaction $(\mathrm{F}=0.8$, $p=0.38)$ emerged for delta values.

\section{Correlation between Cortisol Suppression after Fludrocortisone and Cognitive Performance}

We found a strong correlation $(r=0.45, p<0.01)$ between cortisol suppression after fludrocortisone (delta value) and
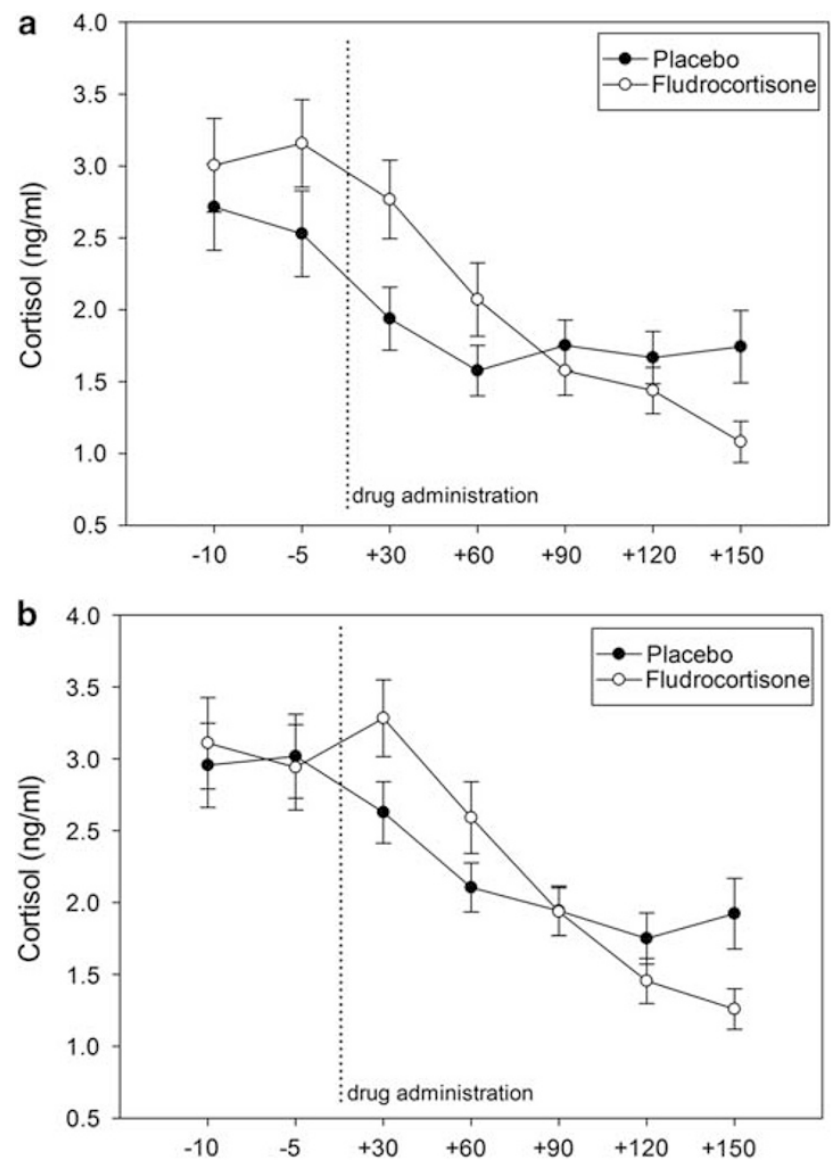

Figure 3 Cortisol secretion after placebo and fludrocortisone; a significant treatment $\times$ time interaction $(F=9.5, p<0.01)$ indicates stronger cortisol suppression after fludrocortisone compared with placebo across groups; (a) healthy controls, (b) depressed patients.

verbal memory retrieval as expressed in percentage of correctly identified items in the delayed recall task of the AVLT (Figure 4). However, no significant correlation between cortisol suppression after fludrocortisone and executive function or visuospatial memory emerged.

\section{Blood Pressure}

There was no significant effect of treatment indicating that fludrocortisone did not increase diastolic $(\mathrm{F}=0.19, p=0.66)$ or systolic $(\mathrm{F}=0.02, p=0.88)$ blood pressure. Furthermore, there was no group effect indicating that depressed patients did not differ in diastolic $(\mathrm{F}=1.1, p=0.29)$ or systolic $(\mathrm{F}=0.73, p=0.39)$ blood pressure values from healthy controls. Finally, we found no group $\times$ treatment interaction on diastolic $(\mathrm{F}=0.24, p=0.62)$ or systolic $(\mathrm{F}=0.19$, $p=0.66)$ blood pressure.

\section{DISCUSSION}

We examined the effect of the MR agonist fludrocortisone on memory, executive function, and cortisol secretion in medication-free depressed patients and age-, sex-, and 


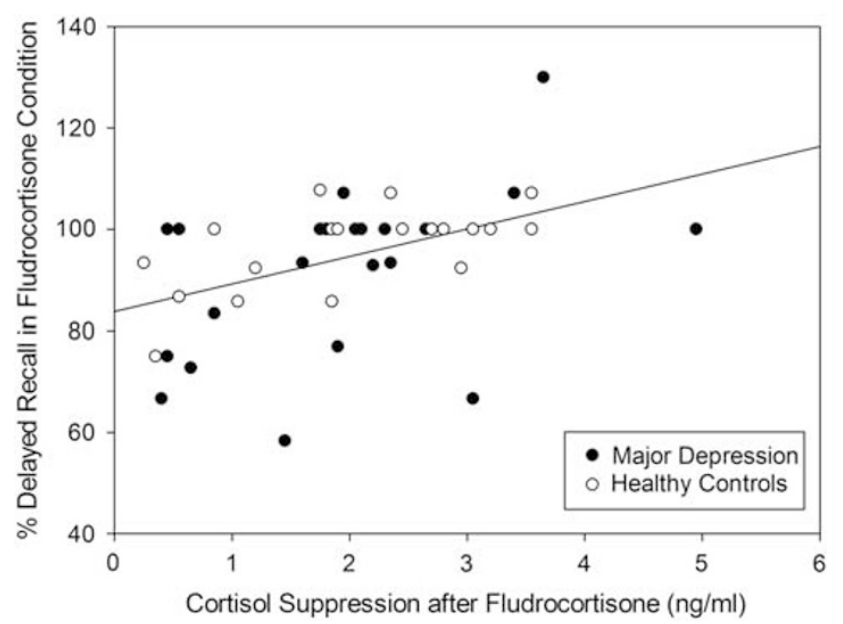

Figure 4 Correlation between cortisol suppression after fludrocortisone and percentage of correct answers in delayed recall of verbal memory in the fludrocortisone condition (across groups: $r=0.45, p<0.01$; healthy controls: $r=0.60, p<0.0$ I; depressed patients: $r=0.4 I, p=0.059$ ).

education-matched healthy participants. We found significantly improved verbal memory and executive function across groups after fludrocortisone compared with placebo. Furthermore, fludrocortisone inhibited cortisol secretion across groups. The magnitude of cortisol suppression after fludrocortisone was strongly associated with verbal memory performance.

Our data suggest that it is possible to acutely improve memory and executive function in depressed patients through MR stimulation. This is biologically plausible because MR expression is highest in the hippocampus and prefrontal cortex, two brain areas crucial for memory and executive function. Of note, memory and executive function are among those domains that are most consistently impaired in depressed patients (Rock et al, 2013; Wagner et al, 2012). Indeed, it has been repeatedly shown that depressed patients exhibit decreased MR expression in hippocampus and prefrontal cortex in post-mortem studies (Klok et al, 2011a; Medina et al, 2013; Qi et al, 2013). Furthermore, polymorphisms and haplotypes of the MR gene have been shown to be associated with depression (Klok et al, 2011b) and to moderate the association between childhood neglect and amygdala reactivity (Bogdan et al, 2012). Also, there was an attenuated cortisol inhibition in psychotic major depression after fludrocortisone also consistent with impaired MR function in these patients (Juruena et al, 2013; Lembke et al, 2013). Indeed, a potentially beneficial effect of fludrocortisone in the treatment of depressed patients was already suggested in a previous study, in which we demonstrated that add-on MR stimulation accelerates the treatment response to standard antidepressants (Otte et al, 2010b). In sum, there is accumulating evidence that MR alteration have a crucial role in major depression. This study extends these findings and suggests that MR stimulation might be a novel therapeutic approach to improve cognitive function and to decrease cortisol secretion in depressed patients.

However, in our current study, we did not find impaired cortisol suppression after fludrocortisone administration in depressed patients compared with healthy controls. This would suggest intact MR function in our depressed patients, as opposed to the well-known GR alterations in depression (Herbert, 2013; Pariante and Lightman, 2008). This is in line with an endocrine study in 12 depressed outpatients that found rather enhanced in contrast to impaired MR function in depressed outpatients (Young et al, 2003). Interestingly, one previous study showed MR alterations in psychotically depressed patients but not in patients with non-psychotic depression (Lembke et al, 2013). Furthermore, impaired MR-mediated cortisol inhibition prospectively predicted treatment resistance in depressed patients (Juruena et al, 2009). It is possible, therefore, that impaired MR function indicates a more severe course of depression but is not necessarily present in patients with non-psychotic depression or without a history of treatment resistance.

Our results concur with recent results from human studies showing that blockade of MR impairs memory function in young healthy men (Cornelisse et al, 2011; Otte et al, 2007; Rimmele et al, 2013). Our findings are also compatible with a recent study demonstrating that predominant MR activation benefits declarative memory consolidation during sleep (Groch et al, 2013). Finally, animal studies have consistently shown that MR overexpression enhances memory (Ferguson and Sapolsky, 2008; Harris et al, 2013; Lai et al, 2007), that MR stimulation enhanced long-term potentiation (Maggio and Segal, 2007), and that reduced hippocampal MR expression is associated with spatial memory impairment (Berger et al, 2006; Brinks et al, 2009; Qiu et al, 2010; ter Horst et al, 2012) and working memory deficits (Berger et al, 2006). Furthermore, the GR antagonist mifepristone antagonist was associated with an increase in cortisol awakening response and with a sustained improvement in spatial working memory performance (Watson et al, 2012). Interestingly, the magnitude of this neuropsychological response was predicted by the magnitude of the cortisol response to mifepristone. The results of that study are compatible with the idea that increased MR signaling in the face of GR blockade is responsible for improved spatial working memory. However, in our study, we used the Rey-Figure that measures immediate and delayed retrieval of visuospatial memory as opposed to spatial working memory. This might at least in part explain why we did not find effects on visuospatial memory. In summary, both animal and human data have now clearly proven an important role of MR function in cognition and our study suggests that it is possible to acutely improve cognition through $\mathrm{MR}$ stimulation.

What might be the mechanisms by which MR stimulation improves verbal memory and executive function? In addition to classical intracellular MR, membrane-bound MR that mediate rapid non-genomic effects have consistently been described (Joels et al, 2008, 2012, 2013). Membrane-bound MR are involved in fast cognitive effects (Khaksari et al, 2007; Schwabe et al, 2010) by promoting glutamate release in the hippocampus and prefrontal cortex (Joels et al, 2008). Therefore, this is a plausible pathway of fludrocortisoneassociated effects on memory and executive function. Furthermore, stimulation of MR inhibits the release of corticotropin-releasing factor (CRF; Muller et al, 2003), 
which in turn is associated with stress-associated cognitive deficits (Wang et al, 2011) and which is increased in patients with major depression (Binder and Nemeroff, 2010; Gold and Chrousos, 2013; Holsboer and Ising, 2010). Therefore, it is possible that CRF inhibition and consecutive lower cortisol values after MR stimulation leads to improved cognitive function. Furthermore, fludrocortisone has some glucocorticoid potency in addition to its mineralocorticoid activity although its MR affinity is about 150 times higher than its GR affinity (Agarwal et al, 1977). The extent of its glucocorticoid potency ranges from negligible to rather moderate depending on the source of the literature and variable being examined (Grossmann, 2004; Miller, 2008). In any event, remaining GR activity could also contribute to the effects of fludrocortisone.

Our study had several strengths. We included a relatively young and homogenous group of depressed patients without current antidepressants, mood stabilizer, or antipsychotics. Furthermore, healthy control participants were carefully matched for age, sex, and education. We measured salivary cortisol parallel to cognitive testing to relate cognitive performance to cortisol secretion during testing. However, several limitations have to be kept in mind when appraising our findings. First, we administered fludrocortisone only once and it is not clear if a longer-term fludrocortisone treatment will exert beneficial effects on memory and executive function. Furthermore, potential side effects need to be considered when weighing potential benefits and risks of fludrocortisone administration. However, this one-time administration of fludrocortisone did not exert any effects on blood pressure in neither of the groups. In the depressed group, $60 \mathrm{~min}$ after fludrocortisone administration, there was a slight cortisol increase before fludrocortisone-mediated cortisol inhibition. Therefore, we cannot completely rule out cross-reactivity between cortisol and fludrocortisone in the laboratory assays. However, this increase was not present in healthy individuals making cross-reactivity less likely. Furthermore, in both groups, cortisol continued to fall after fludrocortisone administration until the last measurement time point and it is possible that between-group differences would have been more pronounced in the later stages of cortisol inhibition after fludrocortisone. Therefore, future studies should measure cortisol for a longer time after fludrocortisone to ensure that complete cortisol suppression is captured. Finally, in our design, we were not able to clearly distinguish between fludrocortisone effects on memory acquisition, consolidation, and retrieval. This is important because in the case of hydrocortisone it has clearly been shown that it enhances memory consolidation but impairs memory retrieval in healthy subjects (Wingenfeld and Wolf, 2011). However, our results indicate that the net effect of fludrocortisone was beneficial on verbal memory as well as on executive function.

In summary, we found beneficial effects of the MR agonist fludrocortisone on verbal memory and executive function in depressed patients and healthy controls. Furthermore, in a recent study, we found beneficial effects of fludrocortisone on empathy in patients with Borderline personality disorder (Wingenfeld et al, 2014). Therefore, stimulating the MR appears to be a new opportunity for cognitive enhancement in health and disease.

\section{FUNDING AND DISCLOSURE}

Dr Wiedemann has served on speakers or advisory boards for Astra Zeneca, Bristol-Myers Squibb, Janssen-Cilag, Lundbeck and Otsuka. The remaining authors declare no conflict of interest.

\section{ACKNOWLEDGEMENTS}

We are greatful for the assistance of Noriko Blaue, Kirsten Huwald, Franziska Eckert, Daniel Friedrich, Marie Mews, Iris Remmlinger-Marten, Kristin Ritter, Stefanie Schweininger, and Aniko Zeisler. Dr Otte was supported by the Deutsche Forschungsgemeinschaft (OT 209/7-1 and EXC 257 NeuroCure). He has received honoraria fees for lectures from Lundbeck and Servier and has received compensation as a member of the scientific advisory board of Lundbeck.

\section{REFERENCES}

Agarwal M, Coupry F, Philippe M (1977). Physiological activity and receptor binding of 9 alpha fluorohydrocortisone. Biochem Biophys Res Commun 78: 747-753.

Behnken A, Bellingrath S, Symanczik JP, Rieck MJ, Zavorotnyy M, Domschke $\mathrm{K}$ et al (2013). Associations between cognitive performance and cortisol reaction to the DEX/CRH test in patients recovered from depression. Psychoneuroendocrinology 38: 447-454.

Berger S, Wolfer DP, Selbach O, Alter H, Erdmann G, Reichardt HM et al (2006). Loss of the limbic mineralocorticoid receptor impairs behavioral plasticity. Proc Natl Acad Sci USA 103: 195-200.

Binder EB, Nemeroff CB (2010). The CRF system, stress, depression and anxiety-insights from human genetic studies. Mol Psychiatry 15: 574-588.

Bogdan R, Williamson DE, Hariri AR (2012). Mineralocorticoid receptor Iso/Val (rs5522) genotype moderates the association between previous childhood emotional neglect and amygdala reactivity. Am J Psychiatry 169: 515-522.

Brinks V, Berger S, Gass P, de Kloet ER, Oitzl MS (2009). Mineralocorticoid receptors in control of emotional arousal and fear memory. Horm Behav 56: 232.

Buckley TM, Mullen BC, Schatzberg AF (2007). The acute effects of a mineralocorticoid receptor (MR) agonist on nocturnal hypothalamic-adrenal-pituitary (HPA) axis activity in healthy controls. Psychoneuroendocrinology 32: 859.

Cornelisse S, Joels M, Smeets T (2011). A randomized trial on mineralocorticoid receptor blockade in men: effects on stress responses, selective attention, and memory. Neuropsychopharmacology 36: 2720-2728.

de Kloet ER (2013). Functional profile of the binary brain corticosteroid receptor system: mediating, multitasking, coordinating, integrating. Eur J Pharmacol 719: 53-62.

Ferguson D, Sapolsky R (2008). Overexpression of mineralocorticoid and transdominant glucocorticoid receptor blocks the impairing effects of glucocorticoids on memory. Hippocampus 18: 1103-1111.

Gold PW, Chrousos GP (2013). Melancholic and atypical subtypes of depression represent distinct pathophysiological entities: $\mathrm{CRH}$, neural circuits, and the diathesis for anxiety and depression. Mol Psychiatry 18: 632-634.

Gomez RG, Fleming SH, Keller J, Flores B, Kenna H, DeBattista C et al (2006). The neuropsychological profile of psychotic major depression and its relation to cortisol. Biolo Psychiatry 60: 472.

Groch S, Wilhelm I, Lange T, Born J (2013). Differential contribution of mineralocorticoid and glucocorticoid receptors to memory formation during sleep. Psychoneuroendocrinology 38: $2962-2972$. 
Grossmann C, Scholz T, Rochel M, Bumke-Vogt C, Oelkers W, Pfeiffer AF et al (2004). Transactivation via the human glucocorticoid and mineralocorticoid receptor by therapeutically used steroids in CV-1 cells: a comparison of their glucocorticoid and mineralocortcoid properties. European J Endocrinology 151: 397-406.

Harris AP, Holmes MC, de Kloet ER, Chapman KE, Seckl JR (2013). Mineralocorticoid and glucocorticoid receptor balance in control of HPA axis and behaviour. Psychoneuroendocrinology 38: 648-658.

Henckens MJ, van Wingen GA, Joels M, Fernandez G (2011). Timedependent corticosteroid modulation of prefrontal working memory processing. Proc Natl Acad Sci USA 108: 5801-5806.

Herbert J (2013). Cortisol and depression: three questions for psychiatry. Psychol Med 43: 449-469.

Hinkelmann K, Moritz S, Botzenhardt J, Riedesel K, Wiedemann K, Kellner $\mathrm{M}$ et al (2009). Cognitive impairment in major depression: association with salivary cortisol. Biol Psychiatry 66: 879-885.

Hinkelmann K, Muhtz C, Dettenborn L, Agorastos A, Moritz S, Wingenfeld $\mathrm{K}$ et al (2013). Association between cortisol awakening response and memory function in major depression. Psychol Med 43: 2255-2263.

Holsboer F, Ising M (2010). Stress hormone regulation: biological role and translation into therapy. Annu Rev Psychol 61: 81-109 C101-111.

Joels M, Karst H, DeRijk R, de Kloet ER (2008). The coming out of the brain mineralocorticoid receptor. Trends Neurosci 31: 1-7.

Joëls M, Karst H, DeRijk R, de Kloet ER (2008). The coming out of the brain mineralocorticoid receptor. Trends Neurosci 31: 1.

Joels M, Pasricha N, Karst H (2013). The interplay between rapid and slow corticosteroid actions in brain. Eur J Pharmacol 719: 44-52.

Joels M, Sarabdjitsingh RA, Karst H (2012). Unraveling the time domains of corticosteroid hormone influences on brain activity: rapid, slow, and chronic modes. Pharmacol Rev 64: 901-938.

Juruena MF, Pariante CM, Papadopoulos AS, Poon L, Lightman S, Cleare AJ (2009). Prednisolone suppression test in depression: prospective study of the role of HPA axis dysfunction in treatment resistance. Br J Psychiatry 194: 342-349.

Juruena MF, Pariante CM, Papadopoulos AS, Poon L, Lightman S, Cleare AJ (2013). The role of mineralocorticoid receptor function in treatment-resistant depression. J Psychopharmacol 27: 1169-1179.

Khaksari M, Rashidy-Pour A, Vafaei AA (2007). Central mineralocorticoid receptors are indispensable for corticosterone-induced impairment of memory retrieval in rats. Neuroscience 149: 729-738.

Klok MD, Alt SR, Irurzun Lafitte AJ, Turner JD, Lakke EA, Huitinga I et al (2011a). Decreased expression of mineralocorticoid receptor mRNA and its splice variants in postmortem brain regions of patients with major depressive disorder. J Psychiatr Res 45: 871-878.

Klok MD, Giltay EJ, Van der Does AJ, Geleijnse JM, Antypa N, Penninx BW et al (2011b). A common and functional mineralocorticoid receptor haplotype enhances optimism and protects against depression in females. Transl Psychiatry 1: e62.

Krogh J, Videbech P, Renvillard SG, Garde AH, Jorgensen MB, Nordentoft M (2012). Cognition and HPA axis reactivity in mildly to moderately depressed outpatients: a case-control study. Nord J Psychiatry 66: 414-421.

Lai M, Horsburgh K, Bae SE, Carter RN, Stenvers DJ, Fowler JH et al (2007). Forebrain mineralocorticoid receptor overexpression enhances memory, reduces anxiety and attenuates neuronal loss in cerebral ischaemia. Eur J Neurosci 25: 1832-1842.

Lembke A, Gomez R, Tenakoon L, Keller J, Cohen G, Williams GH et al (2013). The mineralocorticoid receptor agonist, fludrocortisone, differentially inhibits pituitary-adrenal activity in humans with psychotic major depression. Psychoneuroendocrinology 38: 115-121.
Lezak M (1995). Neuropsychological Assessment. 3rd edn Oxford University Press: New York, NY.

Maggio N, Segal M (2007). Striking variations in corticosteroid modulation of long-term potentiation along the septotemporal axis of the hippocampus. J Neurosci 27: 5757-5765.

Medina A, Seasholtz AF, Sharma V, Burke S, Bunney W Jr., Myers RM et al (2013). Glucocorticoid and mineralocorticoid receptor expression in the human hippocampus in major depressive disorder. J Psychiatr Res 47: 307-314.

Miller (2008). Adrenocorticoids. In: Williams DA (ed.) Foye's Principles of Medicinal Chemistry. 6th edn, Lippincott Williams \& Wilkins, a Wolters Kluwer business: Baltimore, MD, pp 890-891.

Muller MB, Zimmermann S, Sillaber I, Hagemeyer TP, Deussing JM, Timpl P et al (2003). Limbic corticotropin-releasing hormone receptor 1 mediates anxiety-related behavior and hormonal adaptation to stress. Nat Neurosci 6: 1100-1107.

O'Hara R, Schroder CM, Mahadevan R, Schatzberg AF, Lindley S, Fox S et al (2007). Serotonin transporter polymorphism, memory and hippocampal volume in the elderly: association and interaction with cortisol. Mol Psychiatry 12: 544.

Osterrieth PA (1944). Le test de copie d'une figure complexe;contribution a l'etude de la perception et de la memoire (Test of copying a complex figure; contribution to the study of perception and memory). Archives de Psychologie 30: 206-356.

Otte C, Hinkelmann K, Moritz S, Yassouridis A, Jahn H, Wiedemann K et al (2010a). Modulation of the mineralocorticoid receptor as add-on treatment in depression: a randomized, double-blind, placebo-controlled proof-of-concept study. J Psychiatr Res 44: 339-346.

Otte C, Hinkelmann K, Moritz S, Yassouridis A, Jahn H, Wiedemann $\mathrm{K}$ et al (2010b). Modulation of the mineralocorticoid receptor as add-on treatment in depression: a randomized, double-blind, placebo-controlled proof-of-concept study. J Psychiatr Res 44: 339-346.

Otte C, Jahn H, Yassouridis A, Arlt J, Stober N, Maass P et al (2003). The mineralocorticoid receptor agonist, fludrocortisone, inhibits pituitary-adrenal activity in humans after pre-treatment with metyrapone. Life Sci 73: 1835-1845.

Otte C, Moritz S, Yassouridis A, Koop M, Madrischewski AM, Wiedemann $\mathrm{K}$ et al (2007). Blockade of the mineralocorticoid receptor in healthy men: effects on experimentally induced panic symptoms, stress hormones, and cognition. Neuropsychopharmacology 32: 232-238.

Pariante CM, Lightman SL (2008). The HPA axis in major depression: classical theories and new developments. Trends Neurosci 31: 464.

Qi XR, Kamphuis W, Wang S, Wang Q, Lucassen PJ, Zhou JN et al (2013). Aberrant stress hormone receptor balance in the human prefrontal cortex and hypothalamic paraventricular nucleus of depressed patients. Psychoneuroendocrinology 38: 863-870.

Qiu S, Champagne DL, Peters M, Catania EH, Weeber EJ, Levitt P et al (2010). Loss of limbic system-associated membrane protein leads to reduced hippocampal mineralocorticoid receptor expression, impaired synaptic plasticity, and spatial memory deficit. Biol Psychiatry 68: 197-204.

Reitan RM (1992). Trail Making Test. Manual of Administration and Scoring. Reitan Neuropsychology Laboratory: Tuscon, Arizona, USA.

Rimmele U, Besedovsky L, Lange T, Born J (2013). Blocking mineralocorticoid receptors impairs, blocking glucocorticoid receptors enhances memory retrieval in humans. Neuropsychopharmacology 38: 884-894.

Rock PL, Roiser JP, Riedel WJ, Blackwell AD (2013). Cognitive impairment in depression: a systematic review and metaanalysis. Psychol Med (e-pub ahead of print).

Rozeboom AM, Akil H, Seasholtz AF (2007). Mineralocorticoid receptor overexpression in forebrain decreases anxiety-like 
behavior and alters the stress response in mice. Proc Natl Acad Sci USA 104: 4688-4693.

Schatzberg AF, Posener JA, DeBattista C, Kalehzan BM, Rothschild AJ, Shear PK (2000). Neuropsychological deficits in psychotic versus nonpsychotic major depression and no mental illness. Am J Psychiatry 157: 1095-1100.

Schwabe L, Schachinger H, de Kloet ER, Oitzl MS (2010). Corticosteroids operate as a switch between memory systems. J Cogn Neurosci 22: 1362-1372.

Sheehan DV, Lecrubier Y, Sheehan KH, Amorim P, Janavs J, Weiller E et al (1998). The Mini-International Neuropsychiatric Interview (M.I.N.I.): the development and validation of a structured diagnostic psychiatric interview for DSM-IV and ICD-10. J Clin Psychiatry 59: 22-33.

ter Horst JP, van der Mark MH, Arp M, Berger S, de Kloet ER, Oitzl MS (2012). Stress or no stress: mineralocorticoid receptors in the forebrain regulate behavioral adaptation. Neurobiol Learn Mem 98: $33-40$.

Trivedi MH, Greer TL (2014). Cognitive dysfunction in unipolar depression: implications for treatment. J Affect Disord 152-154: 19-27.

van Ast VA, Cornelisse S, Meeter M, Joels M, Kindt M (2013). Time-dependent effects of cortisol on the contextualization of emotional memories. Biol Psychiatry 74: 809-816.
Wagner S, Doering B, Helmreich I, Lieb K, Tadic A (2012). A metaanalysis of executive dysfunctions in unipolar major depressive disorder without psychotic symptoms and their changes during antidepressant treatment. Acta Psychiatr Scand 125: 281-292.

Wang XD, Rammes G, Kraev I, Wolf M, Liebl C, Scharf SH et al (2011). Forebrain CRF(1) modulates early-life stressprogrammed cognitive deficits. J Neurosci 31: 13625-13634.

Watson S, Gallagher P, Porter RJ, Smith MS, Herron LJ, Bulmer $S$ et al (2012). A randomized trial to examine the effect of mifepristone on neuropsychological performance and mood in patients with bipolar depression. Biol Psychiatry 72: 943-949.

Wingenfeld K, Kueh LK, Janke K, Hinkelmann K, Dziobek I, Fleischer $\mathrm{J}$ et al (2014). Enhanced emotional empathy after mineralocorticoid receptor stimulation in women with borderline personality disorder and healthy women. Neuropsychopharmacology 39: 1799-1804.

Wingenfeld K, Wolf OT (2011). HPA-axis alterations in mental disorders: impact on memory and its relevance for therapeutic interventions. CNS Neurosci Ther 17: 714-722.

Young EA, Lopez JF, Murphy-Weinberg V, Watson SJ, Akil H (2003). Mineralocorticoid receptor function in major depression. Arch Gen Psychiatry 60: 24-28. 